\title{
REDES DE SOCIABILIDADE INTELECTUAL E EDUCAÇÃO: ATUAÇÃO DE CASTRO PINTO E CARLOS DIAS FERNANDES NA PRIMEIRA REPÚBLICA
}

\author{
Jean Carlo de Carvalho Costa ${ }^{1}$ \\ Maíra Lewtchuk Espindola ${ }^{2}$ \\ Amanda Sousa Galvíncio ${ }^{3}$ \\ Universidade Federal da Paraíba - UFPB
}

\section{RESUMO}

Este artigo tem como objetivo compreender, a partir da atuação de João Pereira de Castro Pinto e Carlos Dias Fernandes, os mecanismos de ação política e de sociabilidade lançados por esses sujeitos, cujas estratégias privilegiaram a educação como locus fulcral do processo de modernidade. As fontes utilizadas neste estudo foram: as mensagens dos presidentes do estado da Parahyba, os verbetes biográficos, as matérias do jornal A União e as cartas trocadas entre os intelectuais. Castro Pinto concebeu mudanças necessárias para a modernidade do estado a partir da maturação da necessidade de reformas que envolvessem a cidade e a educação, as quais deveriam introduzir novos hábitos e comportamentos no povo. O retorno de Carlos Dias Fernandes ao estado da Parahyba fez parte das reformas empreendidas pelo governo de Castro Pinto. A imprensa oficial, desse modo, assumiu função pedagógica através da circulação de notícias, publicação de novos livros e incentivo à intelectualidade local. Carlos Dias Fernandes desempenhou papel de destaque no cenário cultural local mediante a interlocução das ideias que circulavam nacionalmente e foi representado como mestre da juventude do estado.

Palavras-chave: Educação; Intelectuais; Ação Política; Redes de sociabilidade.

\section{INTELLECTUAL SOCIABILITY NETWORKS AND EDUCATION: PERFORMANCE OF CASTRO PINTO AND CARLOS DIAS FERNANDES AT THE FIRST REPUBLIC}

\section{ABSTRACT}

This article aims to comprehend, from the actions of João Pereira de Castro Pinto and Carlos Dias Fernandes, the mechanisms of political action and sociability released by these individuals, whose strategies gives priority to education as the central locus of the modernity process. The main sources used in this study are: the messages of the presidents of the state of Parahyba, the biographical record cards, the articles of the newspaper $\mathbf{A}$ União and the letters exchanged between the intellectuals. Castro Pinto conceived the need of changes to the modernity of the state as from the maturation of the necessity of reforms that entails the city and the education, which must introduce new habits and behaviors to the people. The return of Carlos Dias Fernandes to the state of Parahyba was part of the reforms undertaken by the government of Castro Pinto. In this way, the official press had assumed a pedagogical function through the circulation of news, the publication of new books and the encouragement for local intellectuals. Carlos Dias Fernandes played a prominent role in the local cultural scene through the interchange of ideas that circulated nationally and he was represented as a master of the youth of the state.

Keywords: Education. Intellectuals. Political Action. Social networks. 
Meu Caro Dr. Castro Pinto [...] Não precisamos só de melhoramentos materiais, é tempo agora de cuidar um pouco dos melhoramentos morais, de educar o Estado, os amigos e os adversários, nos sentimentos de justiça, de moralidade e de respeito à lei, nos princípios da verdadeira democracia. Epitácio Pessoa, 1912.

Meu Caro Dr. Carlos Fernandes [...] Foi um delicado prazer intelectual o que me proporcionou a leitura do seu notável trabalho, - hino soberbo e empolgante entoado ao amor da Pátria, não só pelas idéias e sentimentos que expõe, tão ao sabor do meu próprio de pensar e de sentir, como pelo lavor e sedução da frase que os exprime, pela opulência e originalidade das imagens que os adornam.

Epitácio Pessoa, 1914.

Este artigo é um recorte de duas pesquisas dissertativas ${ }^{4}$ e tem como objetivo destacar as ações de dois intelectuais parahybanos, João Pereira de Castro Pinto presidente do estado (1912-1915) - e Carlos Dias Fernandes - diretor da imprensa oficial parahybana (1913-1925). Ambos foram atuantes no estado da Parahyba ${ }^{5}$ e no Brasil, durante a Primeira República, cujos laços de sociabilidade estão imbricados, como veremos, a partir das relações de amizades e políticas.

Com as reuniões do nosso grupo no HISTEDBR-PB, uma temática começou a nos chamar atenção e se revelou bastante profícua para pesquisas: a atuação dos intelectuais parahybanos na Primeira República. Nesse sentido, tivemos algumas inquietações acerca da atuação dos intelectuais na Parahyba: quem foram esses sujeitos? Quais eram suas ideias educacionais? Qual sua relação com os principais temas envoltos no cenário nacional? O que eles produziram?

Localizamos e coletamos as fontes nos arquivos públicos de João Pessoa ${ }^{6}$. Sobre o processo de produção e organização das fontes, Certaeu (2011) é muito elucidativo, no sentido em que coloca uma importante reflexão para o historiador, levando-o ao entendimento segundo o qual a manipulação desses documentos é parte constitutiva da operação histórica. Isto é, tanto o pesquisador, como os materiais selecionados, estão envolvidos na transformação do uso original em que esse material foi produzido:

Em história, tudo começa com o gesto de separar, de reunir, de transformar em "documento" certos objetos distribuídos de outra maneira. Essa nova distribuição cultural é o primeiro trabalho. Na realidade, ela consiste em produzir tais documentos, pelo simples fato de recopiar, transcrever ou fotografar esses objetos mudando ao mesmo tempo o seu lugar e o seu estatuto. Esse gesto consiste em "isolar" um corpo, como se faz em física, e em "desfigurar" as coisas para constituílas como peças que preencham lacunas de um conjunto proposto a priori. (CERTAEU, 2011, p. 69).

Portanto, compreendemos que nosso movimento investigativo não se realiza de modo apenas subjetivo, mas nos leva a crer que o trabalho historiográfico requer do pesquisador as competências de compreender e dar sentido aos documentos (CERTAEU, 2011; REIS, 2011). Após a localização dos documentos, começamos a coletar os dados por meio da 
leitura e do registro em fichamento, para, em seguida, poderem ser analisados e cruzados com o pensamento dos intelectuais estudados. As fontes selecionadas foram: mensagens dos presidentes do estado da Parahyba; verbetes biográficos; matérias do Jornal A União; e cartas trocadas entre os intelectuais.

A análise das mensagens presidenciais nos forneceu um panorama sobre as ideias e as atribuições dos políticos, nos proporcionando um diálogo entre as propostas educacionais e a atuação de alguns sujeitos nos governos na Parahyba. Visamos, assim, compreender seus posicionamentos voltados para a educação. Além de ampliarmos nosso conhecimento sobre as propostas culturais e educacionais no estado, já que "As mensagens dos presidentes do estado contribuem para a explicação da trama que esteve implicada no processo de produção da escola [...]" (GONÇALVES, 2009, p. 111).

Os verbetes biográficos utilizados como fonte, em especial, de sujeitos que tiveram uma atuação relevante para o estado, nos coloca diante de uma imagem já estabelecida que precisa ser revista, cujo fim não é produzir nem estabelecer uma única verdade, mas consiste em representações que são derivadas de "[...] quem a escreve, do seu tempo e espaço, marcada por instituições e grupos.” (BORGES, 2008, p. 216). Nesses lugares de memória contemporânea, como nos alerta Reis (2012), é preciso questionar qual memória se pretende guardar em detrimento de outras.

As cartas que utilizamos foram fabricadas, tomando de empréstimo o termo de Certaeu (2011), de duas maneiras. As primeiras foram encontradas na biblioteca do IHGP e são provenientes da coleção de documentos de Epitácio Pessoa, cujo intuito obedece ao mesmo princípio mencionado no argumento sobre os verbetes biográficos, sobre as coleções. Malatian $(2009$, p. 202) também nos alerta que: “[...] a conservação de série inteiras por escritores, políticos, artistas e outros no faz pensar em um ato de memória consciente e sondar sua possível interferência sobre a espontaneidade dos escritos.”. As cartas trocadas por intelectuais desse período revelam os grupos sociais em que esses sujeitos transitavam e nos auxiliam a pensar que suas trajetórias não estavam condicionadas apenas pelas relações estabelecidas nos espaços públicos "[...] mas comportam aspectos da vida privada em que se manifestam com clareza no jogo astucioso de ocultar/revelar da narrativa intencionalmente construída embora nem sempre explícito com todas as letras." (MALATIN, 2009, p. 210).

Os jornais, no período estudado, desempenharam um papel crucial "[...] na educação diária das pessoas, mas também na função exercida por eles na própria evolução da sociedade." (CAMPOS, 2012, p. 49). Para Campos (2012), as pesquisas que se utilizam dos jornais como fonte podem observar o modo de produção e circulação dos textos, as atividades desenvolvidas pelos intelectuais na imprensa e a configuração do cenário educacional que se desenhava no Brasil, a partir da metade do século XIX e das primeiras décadas do século XX. Ou seja, essas fontes nos remetem à tradição histórica do seu tempo, sendo possível perceber os temas educacionais relevantes para época, a posição assumida pelos sujeitos nos debates e suas críticas. Os jornais tinham como função movimentar as ideais do período, trazendo para o cotidiano os projetos políticos que disputavam hegemonia na sociedade brasileira. Desse modo, a imprensa pode ser pensada como um lugar privilegiado de disseminação da cultura educacional, pois, foi por meio desses que as ideias eram divulgadas.

Este trabalho está dividido em três seções. Na primeira tratamos da inserção dos estudos sobre intelectuais no campo da história da educação. Em seguida, realizamos uma breve exposição das propostas de Castro Pinto, relacionando- as com processo de modernidade ${ }^{7}$ a Parahyba. Na terceira, abordamos as atribuições desempenhadas por 
Carlos Dias Fernandes na imprensa oficial. E, por fim, apresentaremos nossas considerações sobre esse trabalho.

\section{A História da Educação e os Intelectuais: entre a ação política e as redes de sociabilidades}

A temática dos intelectuais como objeto de investigação tem acumulado discussões nas áreas das ciências sociais, da história e da educação. Essas têm se dedicado a compreender o lugar desses sujeitos na sociedade e suas imbricações políticas (VIEIRA, 2011). Peter Burke (1992), ao discutir as tendências que permeiam a nova história, argumenta sobre a aproximação dos historiadores com questões que, por muito tempo, apenas interessavam aos sociólogos e a outros cientistas sociais. Nesse sentido, a expansão do campo historiográfico implica também repensar as explicações históricas, no que confere às tendências sociais e culturais, aproximando-se de áreas como sociologia, antropologia e política. Dessa forma, podemos observar que a história dos intelectuais se constitui enquanto um campo de diálogo, o qual interage com outras áreas do conhecimento como educação, história, sociologia, política, observado a partir do alargamento do campo historiográfico apontado por Burke (1992).

De fato, um dos desdobramentos desse impacto/reviravolta, analisado em contextos os mais variados, é o entrelaçamento de temas, formas de pensar e possibilidades de aproximação entre áreas aparentemente distintas. De modo geral, essa é uma das questões centrais que envolvem o diálogo entre a História da Educação e a História Cultural, por exemplo e, entre elas, um terceiro espaço tem recebido e conquistado atenção, esse que atravessa ambas e que se pode, a partir também dele, pensar o lugar e o pensamento desses sujeitos, esse obscuro objeto que é a História dos Intelectuais (DOSSE, 2007). Área de investigação que, ao longo do século XX, assistiu o seu objeto ser tratado de formas as mais variadas, inclusive sendo destinado à margem da historiografia e a certo silêncio característico dessa figura, o intelectual, derivado de sua impossibilidade de conviver com a incerteza em relação ao futuro que é imputada à civilização contemporânea (NOVAES, 2006). A despeito disso, também mais recentemente, trata-se de área que reivindica não apenas ser substrato da história enquanto disciplina, mas área autônoma, lugar específico no campo historiográfico em diálogo imprescindível com o político (SIRINELLI, 2003) ${ }^{8}$.

$\mathrm{Na}$ esfera local, essa preocupação é guiada pela análise das diversas consequências derivadas da inserção gradativa do intelectual na esfera pública e no entendimento da constituição do processo de modernização brasileira. Isso tem sido realizado, a partir, por um lado, da investigação das estruturas elementares de sociabilidade desses sujeitos, ou seja, o que produziram, em que lugares trabalharam e publicaram os seus escritos, com quem dialogavam, o que liam, enfim, procurando apreender de que modo certos tipos de inserção (microclimas) possibilitam a ascensão e a queda de ideias produzidas por determinados conjuntos sociais e, por outro, de que forma esses indivíduos, partícipes de uma elite cultural, produziram e mediaram cultura em seus respectivos contextos (SIRINELLI, 1998), constituindo, desse modo, a própria ideia de espaço público. ${ }^{9}$

De certo modo, a ideia dessa intervenção, alicerçada na atribuição de importância destinada ao intelectual apenas se dá se essa é articulada com uma concepção de escola e civilidade que prepondera no século XIX, sintetizada pela ideia de forma escolar (VICENT, LAHIRE \& THIN, 2001) ${ }^{10}$, e que amplia a noção de escolarização e dos elementos constituintes dela quais sejam os tempos, os espaços, os sujeitos, os conhecimentos e as práticas escolares (FARIA FILHO; CHAMON; INÁCIO, 2009). Essa 
profícua abordagem de pensar a educação sugere, do nosso ponto de vista, a necessidade de tratar de forma interdependente esses elementos, a produção intelectual dos atores que nesse período transitam, e aqui situamos jornalistas, escritores, políticos etc., e a própria formação do Estado-nação no Brasil, anunciando o caráter dialógico que caracteriza o pensar sobre o pensamento pedagógico nesse campo e a própria educação que foi forjada ao longo desses últimos dois séculos.

Essa perspectiva se encontra imbricada com a intensificação de estudos recentes internos à historiografia da educação brasileira, os quais relacionam intelectuais, projetos sociais e a educação como eixo principal para o entendimento do papel da instrução e da educação em seus diversos períodos históricos (FARIA FILHO; CHAMON; INÁCIO, 2009; KUHLMANN JR., 2002; VIEIRA, 2006, 2008, 2011).Vieira (2011) argumenta que para o melhor entendimento do conceito de intelectual, no final do Império e início da Primeira República, precisamos delimitar quatro aspectos, a saber:

1) sentimento de pertencimento ao estrato social que, ao longo dos séculos dezenove e vinte, produziu a identidade social do intelectual; 2) engajamento político propiciado pelo sentimento de missão ou de dever social; 3) elaboração e veiculação do discurso que estabelece a relação entre educação e modernidade; 4) assunção da centralidade do Estado como agente político para a efetivação do projeto moderno de reforma social. (VIEIRA, 2011, p. 02).

As pesquisas também demonstram que, além de se configurar como uma opção metodológica, o próprio sujeito, o intelectual, pode ser tomado enquanto objeto de investigação (FARIA FILHO; CHAMON; INÁCIO, 2009; VIEIRA, 2006, 2011). A história da educação enfatiza que esses sujeitos são pertinentes para estudos educacionais, no sentido em que suas atuações como "[...] professoras e professores, literatos, jornalistas e políticos que, atuando como intelectuais, lançando-se na esfera pública e abraçando a causa da instrução, contribuíram para a constituição da educação como uma preocupação pública de primeira grandeza." (FARIA FILHO; CHAMON; INÁCIO, 2009, p. 01).

Segundo Vieira (2006), no caso da educação e, mais especificamente na história da educação, o sujeito intelectual era tomado como objeto que buscava compreender, principalmente, a historiografia do campo. As pesquisas privilegiavam os filósofos e pedagogos nos moldes da genealogia, os cânones dos grandes educadores e as ideais educacionais de sujeitos que marcaram o debate educacional no Brasil. Nesse primeiro momento, entre os anos cinquenta, sessenta e setenta do século XX, a temática foi trabalhada evidenciando a contradição entre católicos e escolanovistas. Se centrando nas ideias educacionais dos sujeitos, sem levar em consideração que essas ideias tinham uma relação profunda com o cenário político e cultural da época (VIEIRA, 2006, 2011).

Entretanto, as pesquisas atuais estão ratificando o deslocamento da atuação desses sujeitos "[...] associando ao movimento de agentes reconhecidos na esfera cultural que se movimentam em direção ao campo político" (VIEIRA, 2011, p. 02), que indica uma "encruzilhada do cultural e do político" (SIRINELLI, 1998, p. 259) como proposta de análise. Nesse contexto, os debates educacionais atravessavam as discussões dos intelectuais brasileiros, cuja ênfase se dava pelo argumento de que a estratégia educativa levaria o país a se tornar uma nação civilizada, tomando o modelo europeu e norteamericano como exemplos (BOTELHO, 1999, 2002, 2005; VIEIRA, 2011). Esse segundo momento das pesquisas busca, nesse sentido, chamar a atenção para a ideia de ação política movida pelos intelectuais (ALONSO, 2002; GOMES, 2009; VIEIRA; 2011). 
Essa posição tem buscado abandonar as perspectivas que entendiam de maneira distinta teoria e prática, levando em consideração que o fazer intelectual desses homens estava estreitamente vinculado a projetos de cunho político. As diversas atividades que compunham suas trajetórias, desde publicação em revistas, jornais, obras literárias, obras de valor historiográfico, projetos de leis e discursos, são parte integrante de formas de pensar e formas de agir (ALONSO, 2002).

A mudança teórico-metodológica, em certa medida, instigou os pesquisadores do século XXI a se debruçarem sobre esses intelectuais a partir de outro olhar, aproximando o sujeito, o político e a escola. Na esteira desse argumento, propomos que esses sujeitos assumiram uma identidade de intervencionistas nas questões cívicas nos espaços públicos, suscitada a partir das suas ações políticas (ALONSO, 2002; GOMES, 2009; VIEIRA, 2006, 2011).

É nesse sentido que Sirinelli (1998, p. 265) chama atenção indicando que: “[...] as elites culturais tomam a cor dos debates cívicos, mas também contribuem para lhes dar os seus tons". As novas pesquisas, diante disso, devem buscar construir uma história social das elites culturais (SIRINELLI, 1998). Esses sujeitos não podem ser pensados enquanto um segmento social em posição de extraterritorialidade, mesmo que, para efeito de análise, seja legitimo isolá-los, mas, é preciso compreendê-los como parte integrante dos arranjos políticos da época: "[...] ligados à sociedade que os rodeias e são precisamente esses laços, especialmente políticos, que lhes conferem uma identidade" (SIRINELLI, 1998, p. 264).

Em nossos estudos sobre Castro Pinto e Carlos Dias Fernandes, seguimos as perspectivas apontadas, pois entendemos que os suas atuações como intelectuais jornalistas, professores, políticos e literatos - se configuram enquanto uma ação política que trouxe à baila propostas educativas, mantendo estreitas ligações com as discussões gestadas em território nacional.

A noção de sociabilidade nos auxiliou a entender as relações instituídas por esses sujeitos no meio político e cultural das ações no estado da Parahyba. Segundo Gomes (2009), foi nos lugares de sociabilidade intelectual - parlamento, jornais e associações que podemos verificar a presença e atuação dos políticos, escritores, editores e livreiros em torno de projetos coletivos comuns. Diante disso:

Flagrar o intelectual na meada de relações que o constitui, atentarmos para os modos de filiação e os lugares de sociabilidade, institucionalizado ou não, onde ocorriam os debates entre eles, auxilia-nos na percepção dos conflitos ou afinidades entre os vários intelectuais de uma determinada época (FARIA FILHO; CHAMON; INÁCIO, 2009, p.10).

Sendo assim, esses sujeitos precisam ser pensados mediante sua imbricação com as questões políticas do seu tempo. O que indica, por um lado, o interesse de um grupo, mas, por outro, mostra-nos suas trajetórias individuais (SIRINELLI, 1998, 2003). Desse modo, esses sujeitos são partícipes da configuração das implementações das propostas educacionais, culturais e políticas que circularam na Parahyba na Primeira República.

Castro Pinto (1963) e Carlos Dias Fernandes (1976) nasceram na segunda metade do século XIX, na cidade parahybana de Mamanguape. Nesse período, segundo Martins (1976), firmaram uma estreita relação de amizade que perdurou pelas suas trajetórias: ambos se formaram na Faculdade de Direito do Recife, instituição consagrada, a qual alguns autores chegam a denominar seus formandos, a partir da década de 1870, como partícipes de uma escola de pensamento, a Escola de Recife (SCHWARCZ, 2010). Todavia, concordamos com Alonso (2002) quando essa estabelece que a Escola de Recife 
foi uma tradição inventada, destacando, ainda, que o termo foi cunhado por Sílvio Romero em 1879.

O estreitamente entre esses dois personagens também se deu mediante a participação nas Associações Culturais do estado, termo cunhado por Martins (1978b) para destacar os espaços criados, a partir de 1880 na Parahyba, cuja finalidade era promover "[...] tertúlia, conferências, festas de caráter cultural e cívico." (MARTINS, 1978b, p. 175).

A primeira e mais importante dessas Associações foi, sem dúvida, o Instituto Geográfico Paraibano (IHGP). No dia sete de setembro de 1905, em uma comemoração à independência do Brasil no Lyceu Parahybano, foi fundado por uma comissão - da qual Castro Pinto participou - o Instituto Histórico Geográfico Paraibano (IHGP). Atuando como orador nessa instituição da sua inauguração até 1909. No discurso inaugural, o orador "[...] demonstrou a necessidade da fundação de um instituto que se consagrasse ao estudo e ao amor do passado [...]". (REVISTA..., 1909, p. 21). Essa foi a premissa dos Institutos Históricos Geográficos no Brasil. Gomes (2009, p. 12) destaca o papel do Instituto Histórico Geográfico Brasileiro (IHGB) "[...] na construção de uma escrita da história e de uma cultura cívica republicana [...]”. Em 1915, Carlos Dias Fernandes tornase membro dessa instituição. Schwarcz $(2010)$ elucida que essas instituições foram pensadas como locus da produção da ciência, procurando formular - utilizando-se de suas escritas e seus discursos - um modelo e uma concepção de nação, focando suas produções para a construção de uma história nacional.

A segunda Associação Cultural na qual Castro Pinto e Carlos D. Fernandes estiveram presentes partícipes foi a Universidade Popular ${ }^{11}$. A referida associação impulsionou, em âmbito local, a realização de conferências que, nesse momento, começaram a fazer parte da dinâmica cultural do estado. A Universidade Popular também marcou o retorno e a consagração de Carlos Dias Fernandes no cenário parahybano, se tornando, nesse período, um conferencista muito requisitado, proferindo sobre diversos temas: economia, educação, higiene, ginástica, feminismo, história do Brasil e da Parahyba, campanha em favor do serviço militar, proteção aos animais, entre outros (GALVÍNCIO, 2013).

E exatamente nesse contexto, quando Castro Pinto assume a presidência do estado, em 1912, que o intelectual trouxe de volta seu conterrâneo, Carlos Dias Fernandes, para dirigir o Jornal A União e a imprensa oficial, como parte das medidas do projeto modernizador para o estado. Nas conclusões da mensagem de 1913, Castro Pinto enumerou os intelectuais que foram chamados para participar do seu governo, destacando:

Seria a mais flagrante injustiça não addicionar a esse meus auxiliares o nome invejavel do maior dos nossos intellectuaes, Dr. Carlos Dias Fernandes, que na direcção do orgam officioso, A União, soube elevar os fóros da imprensa local a uma altura que em tempo algum alcançou, tamanho fulgôr sua festejada penna de jornalista tem dado ás columnas do tradicional periodico do nosso partido. (PINTO, 1913, p. 66, grifo do autor).

Carlos Dias Fernandes reestruturou a imprensa oficial e essa passou a ter destaque no governo de Castro Pinto e nos subsequentes. Castro Pinto renunciou em 1915. No ano seguinte, o jornal A União vinculou matérias elogiando a atuação política de Castro Pinto sob a autoria de Carlos Dias Fernandes.

Castro Pinto e Carlos Dias Fernandes faleceram na cidade Rio de Janeiro, o primeiro em 11 de julho de 1944 e o segundo em nove de dezembro de 1942. Em 1959, 
quando a APL aumentou mais dez cadeiras para seus membros, Castro Pinto tornou-se patrono da cadeira 33 e, em 1964, Carlos Dias Fernandes assume como patrono a cadeira 32.

Ainda destacamos que esses sujeitos, por nós estudados, fazem parte da memória oficial do estado, sendo consagrado pela historiografia local como representantes da intelectualidade parahybana atuantes na Primeira República. A partir desse momento, a intenção do artigo é desenvolver o porquê da importância desses personagens para conformação da educação no estado, através do cruzamento dos ambientes intelectuais comuns (microclimas), os quais configuram uma rede de sociabilidade na qual é possível identificar além de Castro Pinto e Dias Fernandes, a relação desses com outros intelectuais do período. Na seção a seguir, daremos ênfase ao intelectual Castro Pinto e o projeto modernizador empreendido por ele no governo do estado.

\section{As várias faces da modernidade no governo republicano de Castro Pinto na parahyba (1912-1915)}

Entre os anos de 1912 a 1915, o estado da Parahyba foi governado por João Pereira de Castro Pinto. A candidatura para a presidência do estado de Castro Pinto (na época senador) foi lançada por Valfredo Leal e Epitácio Pessoa em 1912, tendo como vicepresidente Antônio Pessoa (irmão de Epitácio Pessoa), agradando as elites políticas locais (machadistas, valfredistas, venancistas e, os nascentes, epitacistas). Trigueiro (1982, p. 34) destaca que "Castro Pinto era bem mais um intelectual brilhante do que um político convencional [...]", fato esse que o levou a tomar posse sem grandes restrições em outubro de 1912. Sua gestão ficou conhecida como uma grande incentivadora da cultura e da educação no estado. Porém, com as eleições nacionais para a Câmara dos Deputados e Senado Federal de 1915, a aliança entre as elites parahybanas cindiu. O intelectual tentou, mediante aos acordos políticos, impedir esse rompimento, pois a unidade política garantia ao estado uma presença nacional. Todavia, Trigueiro (1982, p. 47) afirma que:

Fracassados todas as tentativas de entendimento, Castro Pinto lavou as mãos: ficaria neutro, presidiria ao pleito como magistrado e entregaria o Estado à corrente vitoriosa. Nesses propósitos foi inflexível: a polícia e os serviços estaduais não se imiscuíram na campanha e eleições transcorreram isentas de toda pressão oficial. Exemplo inédito, na Paraíba como no Brasil [...].

Sua atitude desgastou sua imagem tanto no grupo dos venancistas - os quais saíram da eleição derrotados - quanto para os epitacistas e lhe custou a presidência do estado. Renunciou no dia 24 de julho de 1915, deixando a presidência do estado para o vicepresidente Antônio Pessoa.

Durante o seu mandato, além de uma profícua produção de leis e projetos para a reformulação da instrução pública, ocorreu também a criação de uma Universidade Popular, bem como a impulsão das discussões em torno da criação do primeiro grupo escolar, signo da modernização educacional republicana (PINHEIRO, 2001): o Thomaz Mindello. Em um texto historiográfico clássico, José Baptista de Mello (1996, p. 81) destaca que Castro Pinto "[...] via na educação do povo o motivo da sua própria grandeza. Daí a majestade do programa do seu governo." Essa foi uma constante da literatura sobre o seu governo ${ }^{12}$ e há uma consonância de opiniões sobre o grande desenvolvimento ocorrido 
no estado nas áreas de urbanização, educação e direito civil. Espindola (2012, p. 156) conclui que no governo Castro Pinto:

Na Parahyba, a cidade foi pensada dentro do processo de modernidade
multifacetada, no qual diversos saberes se entrelaçaram como a questão
pedagógica, a urbanização, o remodelamento dos espaços, a higiene, a
moralização da força policial e da magistratura, a construção de novas
instituições (como a Universidade Popular) e o remodelamento de outras
(imprensa e biblioteca). Assim como foram criados decretos e leis para a
instituição de uma educação baseada nos preceitos da pedagogia
moderna, com a discussão da criação de novos espaços, da instituição do
método intuitivo, a prescrição de uma literatura didática e de formas para
o estabelecimento da educação física e educação cívica.

Essas foram questões discutidas no Brasil a partir do advento da educação moderna no final do século XIX e início do século XX. Assim a escola, na Primeira República brasileira, passou por uma necessidade de transformação em direção aos novos saberes e às novas técnicas. Logo, as reformas educacionais do período visavam não apenas um aumento da estrutura física das escolas, mas, principalmente, a introdução aos preceitos da educação moderna para o desenvolvimento da sociedade. Percebemos nas mensagens de Castro Pinto, sua preocupação com a necessidade de modernização das escolas parahybanas. Para tal, o presidente do estado destacava a necessidade de investimento financeiro, segundo Pinto (1913, p. 09) "Para conseguir esse desideratum, qual é o do ensino integral, convertendo-se a nossa mentalidade rhetorica e litteraria em senso technico e educação pratica, precisamos augmentar as verbas destinadas á instrucção publica [...]".

Porém, apesar de todo esse entusiasmo pela educação, a não concretização de um sistema educacional na Parahyba e no Brasil levou a muitos intelectuais brasileiros, inclusive Castro Pinto, a se decepcionarem com o projeto republicano, principalmente o voltado para a instrução primária. Segundo Nunes (2010), a partir do contexto do Rio de Janeiro do final da Primeira República, "A modernidade pedagógica definiu a escola pública carioca pela falta: de prédios, de material didático, de professores bem preparados [...] e de modos civilizados e cívicos". Ao tratar da sua decepção com a instrução primária na Parahyba, Castro Pinto percorreu outro caminho, ele não destacou as faltas, mas a não concretização de mudanças:

\footnotetext{
Augmentámos escolas, o numero dos professores cresceu nas folhas de pagamento do Thesouro, houve bôas intenções de administradores honestos e progressistas, as reformas legislativas e regulamentares succedem-se, e o ensino primario de hoje é peior do que o que tinhamos antes da Republica. (PINTO, 1913, p. 10, grifo nosso).
}

Percebemos que o intelectual destacou o aumento de escolas e de professores, além das mudanças nas legislações e regulamentos ocorridas no governo republicano, porém sua análise final foi que havia uma piora da instrução em relação ao Império. Como diagnóstico dessa piora, o presidente do estado citou a falta de implementação de mudanças no ensino público, a falta de fiscalização e a ausência do poder central no incentivo à educação. Porém, o presidente do estado não se aprofundou nessa discussão, deixando apenas um questionamento para nós, que falta de mudanças foi essa que o levou a conclusão da educação ser pior que no Império? O que podemos perceber na sua fala foi a sua decepção com os ideais republicanos para a instrução pública. 
Assim, apesar de um entusiasmo por parte de Castro Pinto em relação à educação, houve uma desilusão com as reformas educacionais ocorridas de fato. Problema esse, que a nosso ver, levou o intelectual a um desencantamento com a própria República, a forma de seu governo e a instrução pública.

Castro Pinto, ainda em seu governo na Parahyba, voltou-se para outro campo: a imprensa. Percebemos que para o presidente havia a percepção da imprensa como aliada a proposta educacional. Ou em suas palavras como uma necessidade superior de cultura (PINTO, 1913), o intelectual justificava as despesas do órgão pela sua importância para a Parahyba, pois traria destaque para a produção parahybana de trabalhos científicos e literários em todo o país. Na mensagem de 1914, Pinto (1914, p. 25) esclareceu que:

Publicando-se alli o orgam official, supeintendido em sua redacção politica pelo partido que apoia o governo, acresce que na secção de obras tenho autorizado a edição de trabalhos scientificos e litterarios que muito tem concorrido para o realce do nome parahybano.

Isso tem augmentado muito as despesas, que incontestavelmente são das mais fecundas e justificadas, tendo-se em vista, além de outras considerações, a repercussão de livros alli publicados na imprensa da Capital Federal e dos Estados.

O presidente do estado destacou algumas de suas publicações como as conferências da Universidade Popular e os opúsculos. Compreendemos, por conseguinte, que essa iniciativa governamental acabou por gerar um movimento de circulação de ideias no estado. E justamente por se caracterizar como uma ação que partiu do governo, não podemos deixar de explicitar que essa circulação foi pensada de forma seletiva e em corroboração com as ideias do partido republicano da Parahyba. Porém, o fato de podermos inferir sobre a seleção desses impressos e dos interesses em suas publicações, não os desclassificam como um movimento de circulação de ideias, tentativa essa ligada a uma modernidade proposta para o estado. Seria no diálogo estabelecido entre a imprensa e a educação que haveria a formação do cidadão. Assim os impressos possuíam uma função dupla, seriam uma fonte de difusão e formação dos cidadãos e também se constituiriam das ideias desses cidadãos. Castro Pinto percebeu a função da imprensa como uma incentivadora do processo de modernidade do estado. E a utilizou como uma forma de projetar o estado para um cenário nacional e para divulgar e formar o povo parahybano.

E é justamente relativa a essa característica da modernidade que percebemos as obras gestadas no governo de Castro Pinto. Tentava-se instaurar na Parahyba novas formas de se pensar as cidades e consequentemente seus cidadãos. Percebemos que havia a necessidade de se articular a sociedade parahybana em torno de um projeto pedagógico, o qual possuía como ponto central o estabelecimento de novos hábitos e posturas diante das cidades. Porém, não podemos deixar de destacar que esse processo de aquisição de novos comportamentos e posturas, também gerava desigualdades. Pensando na modernidade no estado da Parahyba, percebemos como uma das suas características principais o processo de urbanização, o qual segundo Galliza (1993) foi, nas décadas de 1910 e 1920, firmado em duas vertentes básicas: uma econômica, que tinha a preocupação com o desenvolvimento econômico do estado; e uma estética, na qual "[...] havia a preocupação de criar um novo padrão de ordem urbana [...]" (GALLIZA, 1993, p. 122) principalmente na capital do estado. Porém nesse projeto societal, os melhoramentos não foram estendidos a toda a população. Galliza (1993, p. 123) destaca que "[...] com a abertura de avenidas, alinhamento das ruas, criação de praças e, particularmente, o saneamento da Cidade [...]" 
ocorreram diversas desapropriações e a população pertencente às camadas mais pobres foram deslocados dos centros em direção à periferia da cidade. No tópico seguinte, aprofundaremos as questões sobre a imprensa e a atuação de Carlos Dias Fernandes na Parahyba.

\section{Carlos Dias Fernandes e atuação educacional em espaços não escolares}

Carlos D. Fernandes foi embora da cidade de Mamanguape - PB aos 16 anos para estudar farmácia no Recife, financiado pelo seu Tio Avô, José Adolfo de Oliveira Lima. Por esse período, conta Martins (1976, p. 18) que: "Um ano depois voltou a Mamanguape com fumaças de poeta. E conversava literatura com Castro Pinto e Rodrigues de Carvalho." Dias Fernandes viveu em vários estados brasileiros e iniciou sua carreira de jornalista no fim do século XIX, na cidade de São Paulo, escrevendo no jornal Diário Popular. No Rio de Janeiro, trabalhou para diversos periódicos fluminenses: Jornal do Comércio, Gazeta da Tarde, O Debate, A Imprensa - secretariando Rui Barbosa -, e na Cidade do Rio de José do Patrocínio. Ainda na antiga capital nacional estreitou laços com o poeta Cruz e Souza, e na ocasião de sua morte fundou com outros intelectuais as revistas Meridional e Rosa Cruz, em homenagem ao poeta negro.

No início do século XX viveu em terras amazônicas durante 10 anos. Em Manaus se aproximou do intelectual José Veríssimo e em Belém desenvolveu intensas atividades jornalísticas na Gazeta de Belém e dirigindo A Província do Pará. Ali, residiu sob a proteção do político Antonio Lemos, um tipo de mecenas dos homens da inteligência (MARTINS, 1976). A relação com os políticos, como veremos, foi uma estratégia assumida por Carlos D. Fernandes e que marcou toda sua atuação como intelectual, inclusive na Parahyba.

Em 1913 retorna ao estado natal para desempenhar a função de diretor da imprensa oficial. Na capital parahybana, proferiu diversas conferências e publicou livros de gêneros variados: romances, poesias, monografias políticas, opúsculos e livro didático.

A direção da imprensa oficial de Carlos D. Fernandes foi marcada pela agitação cultural no estado, de modo que "[...] o meio literário da província teve vibração até então desconhecida.", como nos diz Trigueiro (1982, p.44), e pelo aumento nos processos de modernização e na produção técnica do jornal (MARTINS, 1978).

Dessa forma, o jornal A União se configurava enquanto uma janela para que as ideias e notícias fossem disseminadas no contexto paraibano. As atribuições designadas para editora oficial também indicam a preocupação de fazer circular no estado livros e obras literárias. Castro Pinto, na ocasião presidente do estado, delegou a seguinte atribuição para imprensa oficial: "[...] na sessão de obras tenho autorizado a edição de trabalhos scientificos e litterarios que muito teem contribuído para o realce do nome parahybano" (PINTO, 1914, p.25).

Barbosa (2007) indica que a circulação das obras se fazia mediante aos anúncios e reclames de vendas de livros nos jornais. A União, seguindo a lógica do mercado editorial posta desde o século XIX, informava seus leitores os locais em que poderiam adquirir os exemplares dos escritos de Carlos D. Fernandes: o poema Myriam (1920) estava sendo vendido nas Casas Andrades, o livro Feminismo (1923) se encontrava na Livraria S. Paulo e A Cultura Physica (1923) na casa PENNA - esses livros também foram editados na gráfica do estado sugerindo, desse modo, o destaque social que Carlos D. Fernandes havia adquirido no cenário paraibano. 
Carlos D. Fernandes, ao dirigir o periódico, lançou mão de outros mecanismos como, por exemplo, a publicação de notas derivadas de outros jornais do período, que noticiavam a circulação dos seus livros em outros estados. Encontramos matérias referentes ao Estado de Pernambuco (PE), o Jornal do Comércio (PE), O Paiz (RJ) e A impressa (RJ). Outra estratégia foi a publicação de cartas que mencionavam a leitura de suas obras. No dia 30 de abril de 1914, o jornal divulgou a seguinte nota:

\begin{abstract}
Ainda hontem chegou às mãos do notável escritor patrício uma carta assignada pelo Sr. José da Silva Dias, residente em Porto Alegre, no Rio Grande do Sul, felicitando-o com grande emoção pelo seu rutilante trabalho Litterario e communicando ter sido lido a conferência Noção de Pátria em sessão do Atheneu Litterario, conceituoso estabelecimento de homens de lettras do Rio Grande Sul, realizada no dia 15 do corrente mez. (ECHOS, 1914, p. 01).
\end{abstract}

Esse trecho, destacado da carta do leitor para Dias Fernandes, nos indica que havia entre os intelectuais da época um forte intercâmbio entre seus livros e ideias. A presença da temática nacional, com ênfase no civismo, foi, sem dúvida, uma preocupação recorrente entre os homens de letras, justificando o sucesso da conferência Noção de Pátria que, no dia 8 de maio de 1914, ganhava as páginas do diário carioca A Imprensa, dirigida por Alcindo Guanabara, com o título: O nacionalismo na Arte ${ }^{13}$.

Em 1924, A União publicou um bilhete que fazia menção à conferência Feminismo, proferida naquele mesmo ano:

Ao Sr. Dr. Carlos D. Fernandes, Maria Virginia da Costa Beata Neves e suas filhas, professoras, agradecem a attenciosa offerta da primorosa conferencia sobre o Feminismo, na qual justa e elevadamente considera os direitos e deveres da mulher, magistralmente interpretado as verdadeiras aspirações femininas. (FEMINISMO, 1924, p. 01).

A questão da educação feminina, nesse período, também foi alvo de muitas discussões educacionais. Enfatizava-se que as mulheres seriam mais aptas, diante da sua sensibilidade maternal, para com os cuidados das crianças, ressaltou José Veríssimo (1985) em Educação Nacional. Carlos Dias Fernandes reservou em seu discurso sobre a mulher a missão de educadora das crianças e protetora dos animais, condizentes com a teoria vegetariana da qual partilhava ${ }^{14}$. As mulheres deveriam civilizar moralmente as crianças e a sociedade para compaixão com os animais e, desse modo, ao mesmo tempo ele incentivava o desenvolvimento intelectual da mulher e a colocava em lugar de destaque na vida pública e da nação.

A discussão em torno da educação proposta por Carlos D. Fernandes estabeleceu relações com as problemáticas paraibanas, mas também dialogava com aspectos importantes da formação nacional do nosso país. O intelectual paraibano evocou no seu discurso a importância do sentimento cívico, mediante a noção de uma língua comum, de uma história compartilhada e do amor à pátria: pilares para construção da nacionalidade.

Carlos D. Fernandes, partilhando desses ideais, argumentou em Noção de Pátria (1914), A Defesa Nacional (1916), Escola Pittoresca (1918), De "rapaizinho" a Imperador (1920) e O problema da instrucção no Brasil (1924) a questão da unificação na nação. Em Infância Proletária (1924), Um professor pragmático (1925) e Puericultura e hygiene infantil (1925) destacou a importância da higiene da mulher e da criança, que, 
segundo Veiga (2007) e Nagle (2009), foram questões de primeira grandeza nas primeiras décadas republicanas. Em Associação Protetora dos Animais (1914) e Vegetarianismo (1916), compartilhou o ideário civilizatório em que o respeito aos animais era uma questão ética e moral, de saúde e higiene; a mulher como educadora da bondade, além de fazer uma apologia à natureza como símbolo principal da nacionalidade.

Trigueiro (1982) ressalta que foi nos anos de 1910 até 1924 que a capital paraibana experimentou uma fase de progresso atrelada à "[...] ampla transformação na mentalidade política e extraordinária movimentação na vida intelectual." (TRIGUEIRO, 1982, p. 57). O autor ainda enfatiza a importância de Carlos D. Fernandes na vida cultural da cidade. Entretanto, o setor econômico do estado era basicamente assentado na criação de gado, algodão, cana-de-açúcar e oscilava entre pragas e secas (TRIGUEIRO, 1982).

Diante isso, a carreira intelectual na Paraíba empurrava os sujeitos letrados a cargos atrelados aos programas políticos locais. Essa mesma dinâmica foi apresentada por Nogueira (2010), argumentando que a formação social brasileira não favoreceu o trabalho intelectual destituído da maquina do Estado. Para o autor, a experiência intelectual no Brasil esbarrava na revolução burguesa conservadora ${ }^{15}$. No período republicando, Carvalho (2001) percebe continuidades em relação às atribuições dos intelectuais brasileiros, destacando o impasse da divisão social do trabalho que estava marcado, sobretudo, por problemas causados pela escravidão. Desse modo, os segmentos sociais deslocados da sociedade escravocrata e que não viviam diretamente dos seus benefícios buscavam no emprego público uma carreira profissional.

Segundo Joffily (1979), na Paraíba, as condições não eram diferenciadas, pois o mundo do trabalho era comandado pelos senhores de terras, não diferindo muito da época da escravidão. $O$ autor também menciona as criticas de Carlos D. Fernandes a essa realidade: "Desde 1915, Carlos D. Fernandes clamava contra o latifúndio e defendia os camponeses sem terra, comparando aquelas relações de trabalho com instituições medievais." (JOFFILY, 1979, p. 123). Nesse sentido, não houve, no período, um favorecimento de funções estritamente liberais, dissociadas das relações políticas.

Carlos D. Fernandes, quando retornou ao estado, se encontrava imerso nessas relações de apadrinhamento político, em troca dos seus serviços intelectuais, mesmo sendo crítico delas. Na atuação de Dias Fernandes, como diretor do jornal A União, foi possível observar como as carreiras intelectuais se formavam ao redor dos setores estatais, pois o próprio jornal, órgão do governo, recebia os meninos da cidade que se destacavam pela sua boa escrita. N'A União, Carlos Dias Fernandes avaliava as condições de escrita dos jovens paraibanos, como destacou Gomes (1989, p. 33):

Conheci Carlos Dias Fernandes quanto aos 17 anos e entrei para A UNIÃO como revisor. Trabalhei de graça um ano inteiro: a esse tempo tinha-se que trabalhar de graça, pelo menos alguns meses a título de aprendizado, para ser nomeado repórter-visor, ganhando duzentos mil réis. Em pouco tempo deixo de ser revisor para ser noticiarista. Carlos Dias Fernandes notou que aquele menino tinha boa letra e escrevia certo. [...] Vez por outra manda chamar esse menino e lhe diz: -Osias, senta aí, pega no "cangaço!".

O cangaço era uma resma de papel imaculado sobre a mesa.

Era uma mesa alta, dessas de guarda livros, meus pés quase não atingiam o chão. Começava a ditar seus notáveis artigos, seus editoriais e "sueltos", as suas notas políticas e literárias, o registro de eventos artísticos ou culturais. 
Nesse sentido, no relato de Gomes (1998), é possível compreender a relação de aprendizado que se estabelecia entre ele, recém-chegado n'A União, e Dias Fernandes, o mestre intelectual que lhe causava tanta admiração. Martins (1976, 1978a) também confirma as memórias de Gomes (1989) dizendo que muitos desses jovens se iniciaram com Dias Fernandes e, posteriormente, assumiriam posição de homens das letras. O presidente de estado, João Suassuna, na mensagem de 1925, reconheceu o jornal A União e os ensinamentos de Dias Fernandes como sendo um grande serviço prestado à educação dos moços paraibanos.

Foi nesse sentido que Dias Fernandes era representado como querido mestre pelos que passaram pela escola d' A União, justificando também a defesa que seus discípulos, anos depois, fizeram em torno da sua personalidade. A posição assumida pelo intelectual na sociedade paraibana ainda estava marcada pelas relações de amizade Camillo de Hollanda (1862-1946) e Epitácio Pessoa (1865-1942).

Na mensagem presidencial do governo do estado, de primeiro de setembro de 1917, Camillo de Holanda reafirma a confiança depositada por Castro Pinto as atividades intelectuais de Dias Fernandes, o nomeando novamente para diretor da imprensa oficial. Ainda no ano de 1918, Camillo de Hollanda, encomenda a Carlos Dias Fernandes um livro didático para ser utilizado nas escolas publicas do estado. Escola Pittoresca, o livro produzido, foi escrito no corrente ano, publicado e editado no Rio de Janeiro, pela Livraria e Editora de Leite \& Maurillo, adotado nas escolas parahybanas pelo Decreto n. 913 de 14 de março de 1918.

As amizades com os ex-presidentes do estado, Castro Pinto e Camilo de Hollanda, e com Epitácio Pessoa, nos sugerem as afinidades estabelecidas por Dias Fernandes com os homens de poder político na Paraíba. Sobre Epitácio Pessoa, Trigueiro (1982) nos diz que ele comandava a política no estado, escolhendo os representantes do governo a partir das suas perspectivas pessoais. Essa fase da política paraibana ficou conhecida como epitacismo. Segundo Raposo (2006), Epitácio Pessoa iniciou sua carreira política em 1889 e sua liderança na Paraíba ficou mais forte após 1915, estando no comando das relações políticas até 1930 .

Encontramos duas correspondências de Epitácio Pessoa endereçadas a Carlos D. Fernandes. A primeira foi escrita quando o político se encontrava em Paris, no dia 9 de março, de 1914. A carta agradecia e elogiava os exemplares enviados de Noção de Pátria (1914a) e Os Cangaceiros (1914c). A segunda carta foi escrita no Rio de Janeiro, em 17 de janeiro, de 1925. O assunto era a finalização de um livro escrito por Epitácio Pessoa, que comentava sobre problemas da edição da obra, das dificuldades de publicação e circulação dos livros na Paraíba, principalmente, pela falta de leitores e de pagamento. Por esses motivos, haveria de editá-lo no Rio de Janeiro mesmo. Ao se despedir de Carlos D. Fernandes, enfatizou a sua satisfação pelo amigo ainda estar à frente da imprensa oficial: "Folgo de vê-lo ainda à testa da Imprensa Oficial. Se o novo governo o dispensasse é que me causaria desprazer. Um abraço do colega e amigo." (PESSOA, 1960, p. 07).

Carlos D. Fernandes ainda escreveu, em 1919, Monografia de Epitácio Pessoa, no mesmo ano da Conferência da Paz, na qual o político exerceu a função de chefe da delegação brasileira e exercia a cargo de presidente da República - entre o quatriênio de 1918-1922. Esse livro também foi publicado no Rio de Janeiro, pelo editor Conde Pereira Carneiro, e nos sugere três questões. A primeira ilustra a confiança que Epitácio Pessoa depositava nas atribuições intelectuais de Dias Fernandes. No ano de 1919, podemos acompanhar, pelas páginas d'A União, a divulgação do livro e as matérias elogiosas a 
Epitácio Pessoa, por exemplo, em 22 de maio de 1919, foi veiculada uma matéria em cujo título chamava atenção para a importância da participação do político na Conferência da Paz: "Na festa da glorificação do gênio latino: um esplendido discurso do embaixador Epitacio Pessôa" (NA SORBONE, 1919, p. 01). A segunda nos indica que a utilização do periódico oficial do estado para divulgação das obras do seu diretor não foi uma estratégia editorial de Dias Fernandes. A terceira corrobora a necessidade que esses intelectuais tinham de deslocamento para a capital do país, como estratégia de tornar visíveis suas publicações mais importantes.

O lugar social ocupado por Carlos Dias Fernandes também pode ser verificado nas edições do jornal A União, através das matérias publicadas com sua autoria que, de modo geral, vinham nas primeiras páginas do periódico. Nas consultas feitas no jornal A União, pudemos perceber que foram características do jornal duas estratégias de fazer circular as informações no cenário paraibano: a primeira visava deixar o leitor em sintonia com o que estava acontecendo no contexto nacional e mundial, através das colunas $A$ vida Carioca, recorrente nos anos de 1913, 1914 e 1916; Crônica do Recife, publicadas no ano de 1913; Boletim do estrangeiro, circulou no ano de 1913; A' Baila, de 1916; e os Telegramasserviço especial d'A União transmitido via Western Telegraph, que chegavam até Pernambuco e atualizavam o leitor paraibano com o que vinha acontecendo em outros países, sendo publicado nos anos de 1913, 1914 e 1916. A segunda estratégia e que também complementava a primeira, nos indica as temáticas relevantes para o periódico, a saber: a política republicana local e nacional e se justificava pela própria finalidade a qual o jornal estava subordinado; a educação como promotora da cura social da nação; e a divulgação literária que, disputava as páginas d'A União com os demais focos, enfatizando e reforçando o movimento intelectual paraibano, assim como os clássicos da literatura moderna.

A União também estabelecia diálogos com outros intelectuais que, mesmo não estando na Paraíba, tiveram seus escritos publicados pelo periódico: Carneiro Leão, Educação da Mulher, Educação do Caracter, Educação Popular e Escola Antiga e Escola Moderna, em 1916; Capistrano de Abreu, Os Guayanazes de Piratininga, em 1917; Olavo Bilac, Um Homem, em 1919; e Lima Barreto, Educação physica, em 1921. Ainda podemos verificar que vários folhetins foram publicados durante esse período: Anna Karênine, de Leon Tolstói, em 1913; Os Cangaceiros, romance regionalista de Carlos D. Fernandes, em 1914; A cidade e as Serras, de Eça de Queirós, em 1916; e, no ano de 1920, Poesia do Bem, de Laura Pessôa. Além de diversos poemas de Olavo Bilac, Carlos D. Fernandes e o Rodrigues de Carvalho.

As estratégias adotadas pela A União, mencionadas anteriormente, indicam a preocupação de fazer circular os ideais civilizatórios no estado, sugerindo para os seus leitores o gosto pela literatura, apresentando nomes importantes do meio intelectual da época, as posturas e condutas dos grandes centros urbanos, a adesão às ideias republicanas e enfatizando os grandes homens da política nacional e local. Diante disso, compreendemos que Carlos D. Fernandes teve grande contribuição no cenário cultural e político da Paraíba, no período por nós estudado. Dias Fernandes foi um sujeito que despertou interesse de políticos, de intelectuais e dos jovens do estado. A União, na sua direção, além de servir como periódico que veiculava as questões políticas da época, também foi o suporte em que divulgou suas obras e legitimou sua autoridade intelectual, os jovens que desfrutaram do seu convívio iniciaram com ele suas primeiras incursões intelectuais, muitos seguindo a carreira de literato e jornalista. 
$\mathrm{Na}$ esteira dessas constatações, sobre a trajetória intelectual de Carlos D. Fernandes, ainda destacamos que suas atribuições na Parahyba não se deram somente em torno d' $\mathbf{A}$ União e a imprensa oficial. Dias Fernandes teve muitas participações públicas nesse cenário, especialmente como conferencista, dando importantes contribuições para educação no estado nos níveis primários, secundários e na formação de professores. Desse modo, pode ser entendido como um mediador cultural, que atuou como disseminador das ideias educacionais nacionais em âmbito local (GALVÍNCIO, 2013), contribuindo no sentido de fomentar na população parahybana o desejo de participação cívica, em especial, o cuidado com a educação das crianças pobres, com a juventude, com a educação da mulher e com a proteção aos animais.

\section{Considerações Finais}

A compreensão das fontes foi uma grande questão a ser trabalhada por nós, (re)construí-las e interpretá-las foi um processo contínuo, no qual fomos diversas vezes aos arquivos e construímos diversos questionamentos. Esse procedimento não poderia ser feito externo ao nosso conhecimento dos contextos históricos dos sujeitos que produziram tal fonte, entender o conhecimento histórico sobre tal momento foi um condicionante importante para a construção dessa pesquisa.

Também, tivemos que eleger uma forma de trabalhar com essas fontes, escolhemos a perspectiva da história dos intelectuais (FARIA FILHO; CHAMON; INÁCIO, 2009; VIEIRA, 2006, 2008, 2011), a partir das noções de ação política (ALONSO, 2002; GOMES, 2009; VIEIRA, 2006, 2008, 2011) e rede de sociabilidades (SIRENILLI, 1998, 2002). Foi, justamente, através das funções desempenhadas por Castro Pinto, político, e Carlos D. Fernandes, jornalista, que esses intelectuais construíram suas redes de sociabilidades, traçando afinidades políticas e culturais. Desse modo, a educação, seja escolar, ou mesmo a oferecida em outros espaços como a leitura de jornais e as associações, faziam parte de um conjunto de dispositivos lançados por esses sujeitos, com o intuito de alçar o Brasil no concerto das nações civilizadas e modernas (BOTELHO, 1999).

Nas nossas análises da atuação de João Pereira de Castro Pinto na Parahyba, percebemos que o intelectual teve duas posturas em relação aos diversos elementos que compunham a Primeira República brasileira: na primeira, foi guiado por uma utopia, cujo objetivo era compor o projeto republicano, sendo a mola propulsora fundamental a educação; na segunda, consequência de seus inúmeros embates nas mais diversas esferas, revelou o seu desencanto com aquele momento idealizado inicial, afastando-se dos cargos representativos e o levando a um autoexílio, do qual saiu raras vezes.Havia uma complementariedade das ações de Castro Pinto para a modernidadeno estado, de um lado procurou instituir novas posturas na população através da cidade e das instituições educativas, de outro incentivou/(re)estruturou a instrução pública no estado.

Castro Pinto reformou a imprensa parahybana e trouxe Carlos Dias Fernandes para atuar dentro de sua proposta de modernidade. O investimento na cultura e na educação e sua interligação com os ideais de modernidade, segundo Vieira (2011), foi um reflexo da percepção que os intelectuais, desse período, tinham sobre a necessidade de mudanças para sociedade brasileira. Havia, portanto, uma consciência da importância da imprensa como local de desenvolvimento tanto da cultura quanto da educação, e por isso instituição indispensável para o projeto republicano de modernidade. Na Parahyba, Castro Pinto mostrou-se consciente do papel da imprensa em educar a sociedade, de promover uma 
circulação de ideias dentro do estado e como instituições incentivadoras da divulgação das ideias parahybanas no âmbito nacional.

Carlos D. Fernandes assim como Castro Pinto tiveram uma participação importante no cenário cultural e educacional da Paraíba, nas primeiras décadas do século XX. Por terem vivido na ambiência intelectual de seu tempo, se engajaram nas questões que mobilizaram o debate público.

Dias Fernandes, imbuído do sentimento de missão pedagógica, acreditava no protagonismo do intelectual e do Estado como instâncias civilizadoras da nação, e na educação como uma estratégia fundamental para modernização do Brasil (BOTELHO, 1999, 2002; VIEIRA, 2011). As ideias gestadas por ele na Parahyba foram propagadas nos principais veículos de comunicação do período - jornais e livros -, derivadas da ascensão do mercado editorial, ficando registradas nos arquivos públicos da cidade de João Pessoa e na história republicana da Paraíba. Nesse sentido, se observa nele um conjunto de elementos privilegiados que nos conduziram no entendimento do processo de circulação de ideias na esfera local, a partir de sua assimilação de tantos temas somada a sua preocupação por disseminar as ideias no universo paraibano.

Além disso, sua atuação intelectual, devido ao fato das suas propostas educacionais, como combate ao analfabetismo, nacionalização do ensino, educação militar, história do Brasil, literatura infantil, higienismo, proteção aos animais e os direitos da mulher, fizeram parte da experiência da geração de jovens, crianças e normalistas no estado e em âmbito nacional.

Por fim, destacamos que revisitar as discussões travadas pelos dois intelectuais parahybanos constituiu-se em um movimento de (re)interpretação e de (re)elaboração sobre a Primeira República brasileira, e particularmente na Parahyba. Para tal, entramos em diversas outras questões como as ligadas a modernidade pedagógica, a nação, a história, a instrução cívica etc. E nesse movimento percebemos como algumas problemáticas passaram a ter uma relevância social.

\section{Referências}

ALONSO, Ângela. Idéias em movimento: a geração 1870 na crise do Brasil-Império. São Paulo: Paz e Terra, 2002.

BORGES, Vavy Pacheco. Fontes biográficas. In: PINSKY, Carla Bassanezi (Org.). Fontes Históricas. São Paulo: Contexto, 2008.

BOTELHO, André. Educação e modernidade no Brasil. Revista Cultura Vozes, São Paulo, v. 93, n. 1, 1999. Disponível em: 〈http://www.ifcs.ufrj.br/ nusc/vozes.pdf〉. Acesso em: 5 out. 2009.

Aprendizado do Brasil: a nação em busca dos seus portadores sociais. Campinas: Editora da UNICAMP, 2002. 2005.

O Brasil e os dias: estado-nação, modernismo e rotina intelectual. Bauru: EDUSC,

BOTO, Carlota. A escola do homem novo. Entre o Iluminismo e a Revolução Francesa. São Paulo: Unesp, 1996.

BURKE, Peter (Org.). A escrita da história: novas perspectivas. Tradução Magda Lopes. São Paulo: UNESP, 1992.

CAMPOS; Raquel Discini de. No rastro de velhos jornais: considerações sobre a utilização da imprensa não pedagógica como fonte para a escrita da história da educação. Revista Brasileira 
de História da Educação, Campinas , v. 12, n. 01, jan/abril 2012. Disponível em: <http://www.rbhe. sbhe.org.br/index.php/rbhe/article/view/320/306> . Acesso em: 10 jun. 2012.

CANDIDO, Antonio. Literatura e Sociedade. Rio de Janeiro: Ouro sobre Azul, 2010.

CARVALHO, José Murilo de. A formação das almas: o imaginário da República no Brasil. São Paulo: Companhia das letras, 2011.

CERTAEU, Michel. A escrita da história. Tradução de Maria de Lurdes Menezes. Rio de Janeiro: Forense Universitária, 2011.

DOSSE, François. La march de las ideias. Historia de los intelectuales, historia intelectual. Valencia: PUV, 2007.

ESPINDOLA, Maíra Lewtchuk. Primeira república, intelectuais e educação: entre a utopia e o (des)encantamento de Castro Pinto (1886-1915). 2012. Dissertação (Mestrado em Educação) - Universidade Federal da Paraíba, João Pessoa, 2012.

FARIA FILHO, Luciano Mendes de; CHAMON, Carla Simone; INÁCIO, Marcilaine Soares. Apresentação. In: FARIA FILHO, Luciano Mendes de; INÁCIO, Marcilaine Soares (Orgs.). Políticos, literatos, professoras, intelectuais: o debate público sobre educação em Minas Gerais. Belo Horizonte: Mazza Edições, 2009.

GALLIZA, Diana Soares. Modernização sem desenvolvimento na Paraíba: 1890-1930. João Pessoa: Idéia, 1993.

GALVÍNCIO, Amanda Sousa. A atuação educacional de Carlos Dias Fernandes na Parahyba do Norte (1913-1925): jornalismo, literatura e conferências. 2013. Dissertação (Mestrado em Educação) - Universidade Federal da Paraíba, João Pessoa, 2013.

GOMES, Ângela de Castro. A República, a história e o IHGB. Belo Horizonte:

Argvmentvm, 2009.

GONÇALVES, Irlen Antônio. Os projetos de educação dos republicanos mineiros. In: VAGO, Tarcísio Marques et al (Orgs.). Intelectuais e escola pública no Brasil: séculos XIX e XX. Belo Horizonte: Mazza Edições, 2009.

JOFFILY, José. Revolta e revolução: 50 anos depois. Rio de Janeiro: Paz e Terra, 1979.

KUHLMANN JR., Moysés. Circulação das idéias sobre a educação das crianças: Brasil, início do século XX. In: FREITAS, Marcos Cezar de; KUHLMANN JR, Moysés (Orgs.). Os intelectuais na história da infância. São Paulo: Cortez, 2002.

MALATIAN, Maria Teresa. Cartas: narrador, registro e arquivo. In: PINSKY, Carla Bassanezi; LUCA, Tania Regina de. O historiador e suas fontes. São Paulo: Contexto, 2009.

MARTINS, Eduardo. A União: jornal e história da Paraíba sua evolução gráfica e editorial. João Pessoa: A União, 1978a.

_. Instituições paraibanas de cultura 1880-1941. Revista da Academia Paraibana de Letras. n. 8, 1978b.

MELLO, José Baptista de. Evolução do ensino na Paraíba. 3. ed. João Pessoa: Secretaria da Educação e Cultura/Conselho Estadual de Educação, 1996.

NAGLE, Jorge. Educação e sociedade na Primeira República. São Paulo: Universidade de São Paulo, 2008. 
NOGUEIRA, Marco Aurélio. O encontro de Joaquim Nabuco com a política: as desventuras do liberalismo. São Paulo: Paz e Terra, 2010.

NOVAES, Adauto. Intelectuais em tempos de incerteza. In: intelectuais. São Paulo: Companhia das Letras, 2006. . (Org.). O silêncio dos

NUNES, Clarice. (Des)encantos da modernidade pedagógica. In: LOPES, Eliane Marta; FARIA FILHO, Luciano; VEIGA, Cyntia. 500 anos de Educação no Brasil. Belo Horizonte: Autêntica, 2010.

PINHEIRO, Antonio Carlos Ferreira. Da era das cadeiras isoladas à era dos grupos escolares na Paraíba. 2001. Tese (Doutorado em Educação) - Universidade Estadual de Campinas, Campinas, 2001. Disponível em: <http://cutter.unicamp.br/document/ ?code $=$ vtls000218787>. Acesso em: 7 ago. 2009.

RAPOSO, Eduardo. 1930: seis versões e uma revolução História da política paraibana (1988-1940). Recife: Fundação Joaquim Nabuco/ Massangana, 2006.

REIS. José Carlos. História da “consciência histórica” ocidental contemporânea: Hegel, Nietzche, Ricoeur. Belo Horizonte: Autêntica, 2011.

_.Teoria\&História: tempo histórico, história do pensamento histórico ocidental e pensamento brasileiro. Rio de Janeiro: Editora FGV, 2012.

RICUPERO, Bernardo. O encontro de Joaquim Nabuco com a política: as aventuras do liberalismo (Resenha). Revista Brasileira de Ciências Sociais, São Paulo, v. 25, n. 74, 2010. Disponível em: $<$ http://www.scielo.br/scielo.php?pid=S0102-69092010000300011\& script=sci_arttext $>$. Acesso em: 10 jan. 2012.

SCHWARCZ, Lilia M. O espetáculo das raças: cientistas, instituições e questão racial no Brasil 1870-1930. 9 ed. São Paulo: Companhia das Letras, 2010.

SIRINELLI, Jean-François. As Elites Culturais. In: SIRINELLI, Jean-François; RIOUX, Jean Pierre (Orgs.). Para uma História Cultural. Tradução Ana Moura. Lisboa: Estampa, 1998

_. Os Intelectuais. In: RÉMOND, René (Org.). Por uma história política. Tradução Dora Rocha. Rio de Janeiro: Editora FGV, 2003

TRIGUEIRO, Osvaldo. A Paraíba na Primeira República. João Pessoa: A União, 1982.

VEIGA. Cynthia Greive. História da educação. São Paulo: Ática, 2007.

VIEIRA, Carlos Eduardo. História dos intelectuais: representações, conceitos e teorias. In: CONGRESSO BRASILEIRO DE HISTÓRIA DA EDUCAÇÃ̃O: A educação e seus sujeitos, 4., 2006, Goiânia. Anais... Goiânia: Editora da Universidade Católica de Goiás, 2006. v. 1. p. 1-10. Disponível em:

<http://www.sbhe.org.br/novo/congressos/cbhe4/coordenadas/ eixo06/Coordenada\%20por\%20Carlos\%20Eduardo\%20Vieira/Carlos\%20Eduardo\%20Vie ira\%20-\%20Texto2.pdf>. Acesso em: 10 ago. 2011.

Intelligentsia e intelectuais: sentidos, conceitos e possibilidades para a história intelectual. Revista Brasileira de História da Educação, n. 16, p. 63-85, 2008. Disponível em: 〈http://www.sbhe.org.br/novo/rbhe/RBHE16.pdf >. Acesso em: 10 ago. 2011.

Erasmo Pilloto: identidade, engajamento político e crenças dos intelectuais vinculados ao campo educacional brasileiro. In: LEITE, Juçara Luzia; ALVES, Claudia (Orgs.), 
Intelectuais e história da educação no Brasil: poder, cultura e política. Vitória: Editora da Universidade Federal do Espírito Santo, 2011.

VINCENTE, Guy; LAHIRE, Bernard \& THIN, Daniel. Sobre a história e a teoria da forma escolar. Educação em Revista, Belo Horizonte, n. 33, junho 2001.

\section{Fontes}

$\underline{\text { Biografia e verbetes biográficos }}$

GOMES, Oasis. Quem foi Carlos Dias Fernandes. In: SANTOS, Idelette Fonseca dos (Org.). A literatura na Paraíba ontem\&hoje. João Pessoa: Fundação Casa de José Américo, 1989.

MARTINS, Eduardo. Carlos D. Fernandes: notícias biobibliográficas. João Pessoa: A União, 1976.

$\underline{\text { Impressos (livros, jornais e revistas) }}$

ECHOS da conferencia "Noção de Pátria". Jornal A União, Parahyba, 30 abr.1914.

FEMINISMO. Jornal A União, Parahyba, 25 set. 1924.

FERNANDES, Carlos Dias. Noção de pátria. Parahyba do Norte: Imprensa Offcial, 1914a.

- Associação Protectora dos Animaes. Conferência realizada no dia 24 de agosto de 1914, no Theatro Santa Roza. Jornal A União, Parahyba, 25 ago. 1914b.

_. Vegetarianismo. Parahyba: Imprensa Oficial, 1916c.

_. Escola pittoresca. Rio de Janeiro: Leite Ribeiro \& Maurillo, 1918.

NA SORBONE. Jornal A União, Parahyba, 22 de maio 1919.

REVISTA DO INSTITUTO HISTORICO E GEOGRAPHICO PARAHYBANO.

Parahyba: Imprensa Officeal da Parahyba, 1909.

VERISSIMO, José. A educação nacional. Porto Alegre: Mercado Aberto, 1985.

$\underline{\text { Cartas }}$

PESSOA, Epitácio. Obras completas de Epitácio Pessoa vol. XX: miscelânea. Rio de Janeiro: Ministério da Educação e da Cultura, 1960.

Obras completas de Epitácio Pessoa vol. XXII: Côrte Permanente de Justiça Internacional (1923-1930). Rio de Janeiro: Ministério da Educação e da Cultura, 1960

\section{Documentos oficiais}

HOLLANDA, Francisco Camillo de. Mensagem apresentada à Assembléia Legislativa do Estado da Parahyba, em $1^{\circ}$ de setembro de 1917. Parahyba: Impressa Official, 1917.

PARAHYBA (Estado). Decreto n. 913, de 14 de março de 1918. Manda adoptar nas escolas primárias o livro didactico intitulado Escola Pittoresca de actoria do Sr. Carlos Revista HISTEDBR On-line, Campinas, $n^{\circ}$ 53, p. 56-77, out2013 - ISSN: 1676-2584 
Dias Fernandes. In: __. Collecção dos actos dos poderes Legislativo e Executivo do Estado da Parahyba em 1918. Parahyba: Imprensa Official, 1918.

PINTO, Castro. Mensagem apresentada à Assembléia Legislativa da Parahyba, de $1^{\circ}$ de outubro de 1913. Parahyba: Imprensa Official, 1913.

Mensagem apresentada à Assembléia Legislativa da Parahyba, de $1^{\circ}$ de setembro de 1914. Parahyba: Imprensa Official, 1914.

Notas

1 Professor Associado I, na área de Fundamentos Sócio-Históricos da Educação, no Departamento de Fundamentação da Educação (Centro de Educação), sendo, atualmente, o Coordenador da área. É professor pesquisador dos Programas de Pós-Graduação em Educação (PPGE) e Sociologia (PPGS), ambos na Universidade Federal da Paraíba (UFPB). Desenvolve pesquisas sobre História Intelectual, Pensamento social e Educação no Brasil. Lidera atualmente o Diretório do Conselho Nacional de Desenvolvimento Científico e Tecnológico (CNPq) Grupo de Estudos e Pesquisas História, Sociedade e Educação no Brasil GT Paraíba (HISTED-BR) e integra também o Grupo de Pesquisa História da Educação no Nordeste Oitocentista (GHENO) E-mail: jeanccosta@yahoo.com.br

${ }^{2}$ Maíra Lewtchuk Espindola é pedagoga, mestre em educação pelo PPGE/UFPB (2012) e doutoranda do PPGE/UFPB (bolsista da CAPES). Membro do HISTED-BR. E-mail:mairalewtchuk@ hotmail.com.

3 Amanda Sousa Galvíncio é pedagoga e mestre em educação pelo PPGE/UFPB (2013). Membro do HISTED-BR. Email: amanda_galvincio@hotmail.com.

${ }^{4}$ A primeira pesquisa foi intitulada "PRIMEIRA REPÚBLICA, INTELECTUAIS E EDUCAÇÃO: entre a utopia e o (des)encantamento de Castro Pinto (1886-1915)", defendida em 2012 no PPGE/UFPB, na linha História da Educação. E teve como objetivo principal "[...] realizar uma interpretação das ações, sobretudo as voltadas para a instrução pública, do intelectual João Pereira de Castro Pinto (1863-1944)" (ESPINDOLA, 2012, p. 13). A segunda foi defendida em 2013, na mesma instituição, com o título de "ATUAÇÃO EDUCACIONAL DE CARLOS DIAS FERNANDES NA PARAHYBA DO NORTE (1913-1925): jornalismo, literatura e conferências", tendo como objetivo principal: “[...] compreender e situar o debate educacional na Primeira República no Brasil, tendo em vista marcar similaridades e particularidades das propostas anunciadas por Carlos Dias Fernandes em exercício comparativo como outros intelectuais brasileiros do mesmo período [...]" (GALVÍNCIO, 2013, p. 21). As duas pesquisas tiveram o financiamento da CAPES (bolsa de mestrado) e a orientação do Professor Dr. Jean Carlo de Carvalho Costa. Essas pesquisas estão, também, atreladas ao HISTEDBR-PB - na linha História Intelectual e dos Intelectuais, (auto)Biografias e Estudos de Gênero - e ao GHENO.

${ }^{5}$ Encontramos, nos arquivos públicos de João Pessoa, duas formas de se referenciar ao estado da Paraíba na Primeira República, a saber: Parahyba do Norte e Parahyba. Como há uma constância maior nos documentos pesquisados da nomenclatura Parahyba, optamos por essa escrita no artigo.

${ }^{6}$ Instituto Histórico e Geográfico Paraibano (IHGP); Arquivo Histórico do Estado da Paraíba (Fundação Espaço Cultural); Biblioteca Álvaro de Carvalho da Academia Paraibana de Letras; Hemeroteca do Arquivo Judiciário; Núcleo de documentação e Informação Histórica e Regional (UFPB); Biblioteca Álvaro de Carvalho da Academia Paraibana de Letras (APL).

${ }^{7}$ Vieira (2011) identifica uma preocupação dos intelectuais com o processo de modernidade, dessa forma, a cidade seria o locus privilegiado do processo de modernidade e a educação uma peça chave para o seu desenvolvimento. Dessa forma, a modernidade que se instaurou com o Império e com a Primeira República, trouxe como um dos seus projetos a questão educacional, a qual foi pensada como um movimento basilar para o desenvolvimento da nação. Nunes (2010) traz um termo que nos parece bastante adequado para entender o período, a saber: modernidade pedagógica. Ao definir esse conceito, a autora centra-se nas práticas escolares das instituições cariocas a partir dos intelectuais renovadores da década de 1910. Assim, a modernidade pedagógica foi um processo no qual a escola e a sociedade caminhavam para o projeto civilizador moderno a partir dos preceitos da ciência. Saindo, por conseguinte, do campo do particular (casa, família) para o campo do público (prédios escolares e reformas educacionais). Seguindo na esteira desses argumentos, compreendemos o conceito de modernidade pedagógica a partir da interligação da modernidade e da educação. O qual se refere não apenas a introdução de uma pedagogia moderna para as escolas, mas 
também na junção de outros elementos como a organização do espaço, das leis e da cientificidade da sociedade. Elementos, esses, que não se interligam apenas na escola, mas também em outros espaços de socialização, como por exemplo, as cidades (ruas, praças, bibliotecas etc.), as assembleias, as associações e as conferências, etc. Lugares que se tornariam pedagógicos, nos quais, através da adoção de uma postura moderna (do espaço e do corpo), poderiam trazer para o país um desenvolvimento societal.

${ }^{8}$ Carlos Eduardo Vieira (2008), em artigo denominado Intelligentsia e intelectuais: sentidos, conceitos e possibilidades para a história intelectual, elaborou uma útil síntese das formas mais tradicionais de abordálo, destinando a sua atenção às forjadas ao longo do século XX através dos olhares de Mannheim, Gramsci e, mais recentemente, Pierre Bourdieu. Em manuscrito mais recente (VIEIRA, 2011), em uma análise sobre a trajetória de um intelectual paranaense, avança no contributo de tradição mais próxima da historiografia e da ciência política contemporânea a partir das obras de Quentin Skinner e John Pocock, esboços da tradição de Cambridge, bem como de Jean-François Sirinelli, responsável, junto com René Rémond, por uma espécie de retomada das investigações sobre os intelectuais a partir de uma abordagem prosopográfica.

${ }^{9}$ De acordo com Antonio Candido (2010, p. 91), a constituição do público, no século XIX e início do século $\mathrm{XX}$, era formada por grupos heterogêneos, muitos desses sujeitos apenas tinham acesso ao que se veiculava nos impressos mediante a leitura coletiva: "A ação dos pregadores, dos conferencistas de academia, dos glosadores de mote, dos oradores na comemoração, dos recitadores e de toda hora correspondia a uma sociedade de iletrados, analfabetos ou pouco afeitos à leitura. Desse modo, formou-se, dispensando o intermédio da página impressa, um público de auditores, muito maior do que se dependesse dela e favorecendo, ou mesmo requerendo, no escritor, certas características de facilidade e ênfase, certo ritmo oratório que perpassou timbre de boa literatura e prejudicou entre nós a formação dum estilo realmente escrito para ser lido. A grande maioria dos nossos escritores, em prosa e verso, fala de pena em punho e prefigura um leitor que ouve o som de sua voz brotar a cada passo por entre as linhas".

${ }^{10}$ A ideia de forma escolar em Vicent, Lahire e Thin (2001) diz respeito ao fato de que a configuração e a difusão da instituição escolar no mundo moderno realizam-se, do ponto de vista desses autores, pela crescente ampliação da influência desta para muito além dos muros da escola. Ou seja, eles afirmam certa dialogicidade que atravessa a modernidade em relação à necessidade de se pensar a escola, legado da utopia revolucionária francesa (BOTO, 1996), e o próprio pensamento sobre ela por alguns desses sujeitos no Brasil oitocentista.

${ }^{11}$ Para mais informações sobre a Universidade Popular na Parahyba ver Espindola (2012).

${ }^{12}$ Ver: Trigueiro (1892); Pinheiro (2001).

${ }^{13}$ É importante ressaltar que, no final do século XIX, Carlos D. Fernandes trabalhou no jornal A Impressa secretariando o renomado intelectual Rui Barbosa (MARTINS, 1976).

${ }^{14}$ Sobre a questão do vegetarianismo em Carlos Dias, ver Galvíncio (2013).

15 Nogueira (2010) teve como hipótese central do seu trabalho, segundo Ricupero (2010), a atuação de Joaquim Nabuco na vanguarda da revolução burguesa no Brasil: O pernambucano teria assumido o caráter de intelectual orgânico da burguesia brasileira que se caracterizava pelo conservadorismo.

Recebido em setembro-13

Aprovado em novembro-13 